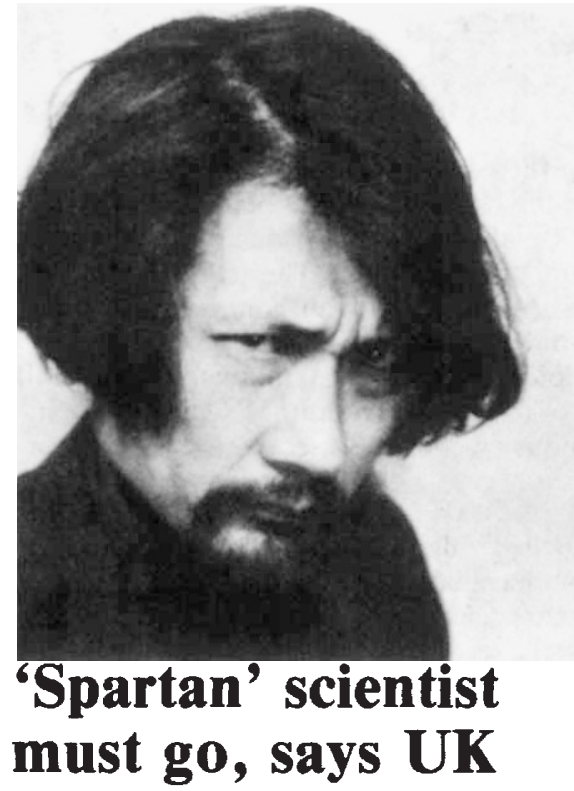

Dr Tetz Yoshimura (above), the Japanese mathematical physicist, who seeks to stay in Britain and pursue his research undisturbed by the 'rat race' of modern Japanese life, is to be deported from Britain. His appeal against deportation was rejected last week by the Home Office on the grounds that his position "presents insufficient unusual features to justify giving him favourable treatment"

This represents a shift in standpoint from previous Home Office notifications, which rejected his application to stay on the grounds that his income from freelance coaching and translation work was insufficient to maintain him. Although Dr Yoshimura's spartan life-style allows him to maintain himself on $£ 12$ per week (half his average income), further guarantees were required. When the author Russell Hoban came forward as financial guarantor, the Home Office dropped the financial aspect, and turned to the fact that Dr Yoshimura's various academic committments had terminated - not surprisingly, since coaching and the marking of examination papers is not normally required during the long vacation.

It seems strange that the Home Office claims the case exhibits no unusual features. Dr Yoshimura is an example of a now almost extinct race of scientists who hope to work without the support of major public funding bodies. When he came to Britain in 1971, he hoped to find a haven of academic detachment. Even the bulky file of correspondence on his case contains the occasional off-print or letter from an academic publisher about the proper placing of a bracket, that have somehow crept into the official hassling.

Faced with the final deportation order, Lord Avebury, chairman of the inter-party parliamentary Human Rights Group told Nature that he hoped that Dr Yoshimura's scientific colleagues would bring all possible pressure on the Home Secretary to reverse his decision.

\title{
Controls urged on mineral fibre
}

A unique government-industry-trade union working party organised by the UK Health and Safety Executive has proposed controls on mineral insulation wools used as substitutes for asbestos, and called for a programme of research to define further the hazards of fibres.

The report estimates that 15,000 workers are involved in the production and steady use of man-made mineral fibres (MMMFs) with up to 250,000 workers coming into "occasional" contact with MMMFs. In addition, the Chairman of the Party, D J Evans estimates that perhaps 20 times this number handle the materials privately.

The fibres are produced from glass, rock, slag and metallic oxides and include fibreglass and rock and slag wools which are widely used for home insulation as a substitute for asbestos. The proposed limits are a fibre limit of five fibres $/ \mathrm{ml}$ and a mass limit of $5 \mathrm{mg} / \mathrm{m}^{3}$. (The present limits for asbestos exposure are 2 fibres $/ \mathrm{ml}$ which is expected to be lowered to $1 \mathrm{fibre} / \mathrm{ml}$ shortly. The National Institute for Occupational Safety and Health in the US has proposed a new limit of 0.1 fibre $/ \mathrm{ml}$.) The time for introduction of the MMMF standard is "not to exceed three years"'.

In separate appendices, the trade union and industry representatives express the fundamental conflict in hazards legislation over who is to pay - industry in the form of safer equipment, or the work force in terms of poor health and possibly early death. Industry contends that no hazard has been shown to exist and as such controls must be based strictly on cost. "In the absence of a scientific basis upon which any changes in the (general dust standard) can be made, any change must be based upon what is considered to be the best practicable engineering controls."

Industry is willing however to support the introduction of a standard. "While emphasising the absence of a scientific basis for the figure we accept the proposed standard of 5 fibres/ml." This standard is not expected to affect industry operations significantly.

\section{Asbestos, not glass fibre, killed woman}

Scientists at the US National Institutes of Health announced last week that a case of pneumoconiosis reported by Japanese research workers last autumn as possibly being related to exposure to glass fibre had turned out to be the result of previous exposure to asbestos. The link between glass fibre and pneumoconiosis had been suggested by a Japanese research worker at a meeting last year held under the auspices of the National Cancer Institute, following his discovery of physiological damage in the lungs of a woman who had worked with glass wool similar to the damage caused by asbestos fibres.
In their statement the TUC states that it would prefer a standard of $1 \mathrm{fibre} / \mathrm{ml}$ and feels it could live with a standard of 3 fibres/ml as "an acceptable and attainable standard under present engineering control knowledge." The TUC disagrees with the 5 fibre/ml standard and it also disagrees with the three year lead-in period, calling instead for adoption of the standards within 12 months.

In the middle of the political fight between those who assign the limits, and those who bear the risks, stand the scientific specialists. In the UK, research into the hazards of fibreglass is being conducted at three places. In Southampton, Professor Donald Acheson will conduct human epidemiological studies. In Edinburgh, the Institute of Occupational Medicine is working on standardisation techniques, and at Penarth a Medical Research Council unit will conduct animal studies as well as designing measurement devices. Additional research is being conducted by the industry funded. International Agency for Research into Cancer with support of the World Health Organisation.

Experienced health and safety observers, however, point out that the situation bears an uncomfortable resemblance to the history of asbestos. In the UK, the first cases of asbestosis were reported by lay people in 1898, and the government noted cases of death in 1900 . But the first legislation was not introduced until 1931, and widespread public awareness of the extent of the hazard did not occur until the 1970s. Fibreglass and its cousins are relatively recent materials and the historical data may not even exist.

Dr Morris Greenberg, medical adviser to the Health and Safety Executive thinks that the situation is difficult. "We think that MMMFs are not in the same league as asbestos but we don't know how far down the leage table they are." Joe Schwartz Man-made Mineral Fibres. Report of a Working Party to the Advisory Committee on Toxic Substances. HMSO. 50p.
The report received considerable publicity, and generated wide concern in the glass fibre industry. However the NIH reported last week that microscopical analysis of biopsy material carried out by Dr I J Sellikoff of the Mount Sinai School of Medicine showed the presence in the lung of asbestos fibres, tut not glass fibres.

The NIH report says that during discussion of the original report, it was understood that six other cases of pulmonary disease had been found. "The existence of these cases cannot be confirmed and is attributed to a linguistic error", the NIH says. 